\title{
Association of body mass index with the outcomes of retrograde intrarenal surgery
}

\author{
Vücut kitle endeksi ile retrograd intrarenal cerrahi sonuçları arasındaki ilișki \\ Volkan Selmi i , Sercan Sari ${ }^{1}$, Mehmet Caglar Cakici ${ }^{2}$, Harun Ozdemir ${ }^{3}$, Ibrahim Guven Kartal ${ }^{4}$, \\ Muhammed Abdurrahim Imamoglu ${ }^{5}$ \\ 1 Bozok University, Faculty Of Medicine, Department Of Urology, Yozgat, Turkey \\ 2 Medeniyet University, Göztepe Training And Research Hospital, Faculty Of Medicine, Department Of Urology, Istanbul, Turkey \\ 3 Avcılar State Hospital, Department Of Urology, Istanbul, Turkey \\ 4 Kütahya Dumlupinar University, Faculty Of Medicine, Department Of Urology, Kutahya, Turkey \\ 5 Dıșkapı Yıldırım Beyazıt Training And Research Hospital, Department Of Urology, Ankara, Turkey
}

\begin{tabular}{|c|c|}
\hline \multicolumn{2}{|c|}{ 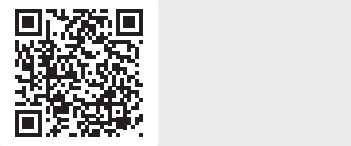 } \\
\hline Submitt & 2020-10-07 \\
\hline Accepted & $020-12-09$ \\
\hline \multicolumn{2}{|c|}{ Yazıșma / Correspondence } \\
\hline \multicolumn{2}{|c|}{ Volkan Selmi } \\
\hline \multirow{4}{*}{\multicolumn{2}{|c|}{$\begin{array}{l}\text { Medrese Mahallesi Adnan Menderes } \\
\text { Bulvarı, Atatürk Yolu 7. Km D:118, } \\
\text { 66200, Azizli, Yozgat / Turkey } \\
\text { e-mail: volkanselmi@hotmail.com } \\
\text { T: +90 } 5327480757\end{array}$}} \\
\hline & \\
\hline & \\
\hline & \\
\hline \multicolumn{2}{|l|}{ ORCID } \\
\hline V.S. & 0000-0003-2605-9935 \\
\hline S.S. & 0000-0002-0994-3799 \\
\hline M.C.C. & 0000-0003-3848-7312 \\
\hline H.O. & 0000-0002-3071-910X \\
\hline I.G.K. & $0000-0002-2313-3522$ \\
\hline M.A.I. & 0000-0003-3848-7312 \\
\hline
\end{tabular}

\section{cc) (i) (8)}

This work is licensed under a Creative Commons Attribution-NonCommercial 4.0 International License.
Özet

Amaç: Obezite, son kırk yılda dünya çapında artış göstermiştir. 2016'da, 18 yaşın üzerindeki erkeklerin yaklaşık \%11'i ve kadınların \%15’i obezdi. Obezite böbrek taşları için bir risk faktörü olarak kabul edilmektedir. Obezite ve ürolitiyazis arasındaki ilişki karmaşıktır. Obez hastalarda perioperatif veya postoperatif takipte çeşitli komplikasyonlar ortaya çıkabilir. Retrograd Intrarenal Cerrahi (RIRS), minimal invaziv yapısı ve yüksek etkinliği nedeniyle obez hastalar için güvenli ve daha az morbid bir tedavi seçeneği olarak kendini göstermektedir. Bu çalışmada, farklı Vücut Kitle İndeksi (VKİ) seviyelerindeki böbrek taşlarının tedavisinde RIRS prosedürünün etkililiğini ve güvenliğini karşılaştırmayı amaçladık.

Gereç ve Yöntemler: Ocak 2012 - Aralık 2017 tarihleri arasında böbrek taşı nedeniyle RIRS yapılan 552 hastanın dosyaları incelendi. Dünya Sağlık Örgütü sınıflandırmasına göre normal kilolu hastalar Grup 1, fazla kilolu hastalar Grup 2 ve obez hastalar Grup 3 olarak sınıflandırıldı. Bu üç grup taşsızlık oranı, komplikasyon oranı, ameliyat ve floroskopi süreleri ve hastanede kalış süreleri açısından karşılaştırıldı.

Bulgular: Çalışma popülasyonunun taşsızlık oranı (SFR) \% 80,8 idi. Grup 1 için \% 81, Grup 2 için \% 83,7 ve Grup 3 için \% 77,7 idi. Üç grup arasında SFR arasında istatistiksel olarak anlamlı fark yoktu $(p=0,366)$. Klinik önemsiz rezidüel
Abstract

Objective: Overweight and obesity increased worldwide over four decades. In 2016, nearly $11 \%$ of men and $15 \%$ of women over 18 years old were obese. Obesity is accepted as a risk factor for renal stones. The relationship between obesity and urolithiasis is complicated. Various complications can occur during perioperative or postoperative follow-up in obese patients. Minimal invasive nature and high efficacy of Retrograde Intrarenal Surgery (RIRS) present itself as a safe and less morbid treatment option. In this study, we aimed to compare the efficacy and safety of RIRS in the treatment of kidney stones in different BMI levels.

Material and Methods: Files of 552 patients who underwent RIRS for renal stones between January 2012 and December 2017 were reviewed. We classified patients according to the World Health Organisation classification. These three groups were compared for stone-free rate, complication rate, operative and fluoroscopy times and length of hospital stay.

Results: The stone-free rate (SFR) of the study population was $80.8 \%$. It was $81 \%$ for Group 1, $83.7 \%$ for Group 2 and $77.7 \%$ for Group 3. There was no statistically significant difference between the three groups among SFR $(\mathrm{p}=0.346)$. Clinical insignificant residual fragments (CIRF) status was also similar among the three groups $(\mathrm{p}=0.254)$. Complication rates between the three groups were

This study has been conducted retrospectively. All research was performed in accordance with relevant guidelines/regulations, and informed consent was obtained from all participants. 
fragman (CIRF) saptanan hasta sayısı da üç grup arasında benzerdi $(\mathrm{p}=0.254)$. Üç grup arasındaki komplikasyon oranları istatistiksel olarak benzerdi $(\mathrm{p}=0,416)$.

Sonuç: Bu çalışmada obez bireyler de dahil olmak üzere RIRS’nin tüm ürolitiyazis hastaları için uygun bir seçenek olduğunu gösterdik. Obez hastalarda taşsızlık oranları, hastanede kalış süreleri, ameliyat süreleri ve komplikasyon oranları obez olmayan hastalarla benzerdir.

Anahtar Kelimeler: ürolitiyazis, obezite, lazer litotripsi statistically similar $(\mathrm{p}=0.416)$

Conclusion: In this study, we have shown that RIRS is a suitable option for all urolithiasis patients, even for obese individuals. Stonefree rates, length of hospital stay, operation time and complication rates in obese patients are similar with non-obese patients.

Keywords: urolithiasis; obesity; laser lithotripsy

\section{INTRODUCTION}

Overweight and obesity increased worldwide over four decades. In 2016, nearly $11 \%$ of men and $15 \%$ of women over 18 years old were obese. Obesity increases the risk of coronary heart disease, type 2 diabetes mellitus, ischemic stroke and some types of cancer. Also, it has some metabolic effects like hypertension, hyperlipidemia, insulin resistance and accepted as a risk factor for renal stones (1). Powel et al. had searched the relationship between obesity and urolithiasis in 5942 patients and reported higher excretion rates of calcium, oxalate and uric acid, which lead to forming kidney stones (2). However, actual studies have stated that this relationship is more complicated than explained before. Risk of stone formation is higher in morbidly obese patients than obese patients, so a classification should be made between body mass index (BMI) levels. Also, genetics, metabolism, underlying diseases, medications, high calory intake, sedentary lifestyle and socioeconomic status are important causes of urinary stone formation (3).

Various complications can occur during perioperative or postoperative follow-up in obese patients. Due to the metabolic disorders, myocardial ischemia and infarction, deep vein thrombosis and pulmonary embolism, worse wound healing and infections may be found and increases the surgical risk (4). Especially for SWL treatment it is hard to focus the renal stone because of the skin-to-stone distance is longer also for PNL treatment accessing to the collecting system is challenging and longer instruments may be necessary (5). Also, prone positioning of the patient can lead to anaesthesia associated complications (6). Conversely, minimal invasive nature, short hospital stay and high efficacy of Retrograde Intrarenal Surgery (RIRS) procedure present itself as a good, safe and less morbid alternative treatment option for obese patients.

In this study, we aimed to compare the efficacy and safety of RIRS procedure in the treatment of kidney stones in different BMI levels.

\section{MATERIAL AND METHODS}

All procedures in this study were performed under the Declaration of Helsinki and its later amendments. Informed consent was obtained from every patient about the RIRS procedure preoperatively. Files of 552 patients who underwent RIRS for renal stones between January 2012 and December 2017 were reviewed. Preoperative data as gender, age, BMI, stone location, stone size and stone number; perioperative and postoperative data as operation time, fluoroscopy time, residual fragments, stone-free, complications and hospital stay were collected retrospectively.

According to the classification of World Health Organisation, patients with BMI between 18,5 and 24.9 $\mathrm{kg} / \mathrm{m} 2$ were classified as normal weight; BMI between 25 and $29.9 \mathrm{~kg} / \mathrm{m} 2$ as overweight and BMI $30 \mathrm{~kg} / \mathrm{m} 2$ and greater as obese. We classified normal weight patients as Group 1, overweight patients as Group 2 and obese patients as Group 3, according to the World Health Organisation classification.

All patients were evaluated with X-Ray, urinary ultrasound (USG) and Computerized Tomography (CT) and the stone size was calculated by the maximum diameter of the renal stone. For multiple renal stones, the sum of all maximal diameters of each stone was recorded. All patients underwent urine culture and urine analysis. Patients who had urinary infection were treat- 
ed with appropriate antibiotics and underwent surgery after the urine culture was sterile.

All procedures were performed under general anaesthesia. Initially, a 0.035 -inch guidewire was placed in the renal pelvis with a semirigid ureteroscope. Diagnostic ureteroscopy was performed to exclude a ureteral stone and provide ureteral dilatation. Under fluoroscopic control, an access sheath (9.5/11.5 F or 11/13 F) (Elit Flex, Ankara, Turkey) was placed just below the ureteropelvic junction. A flexible ureteroscope (Flex-X2, Karl Storz, Tuttlingen, Germany / Karl Storz, Flex X2, GmbH, Tuttlingen, Germany) was pushed forward through the access sheath, and all the collecting system was visualized. The stone was fragmented or dusted by a $200 \mu \mathrm{m}$ holmium laser probe (Ho YAG Laser; Dornier MedTech; Munich, Germany / Dornier Med-Tech GmbH, Medilas H20 and HSolvo, Wessling, Germany) at 8-10 Hz. Frequency and 1.0-1.8 joule ( $\mathrm{j}$ ) power. The collecting system and residual fragments were checked under fluoroscopy and direct vision then a double J (DJ) ureteral stent was placed. After 2-4 weeks, DJ ureteral stents were displaced.

Operation time was recorded by the insertion of semirigid ureteroscope and placement of DJ ureteral stent. Also, fluoroscopy time, perioperative and postoperative complications were recorded. Stonefree status was evaluated with X-Ray on the first postoperative day and CT on the third month after surgery. Residual stone fragments $\leq 2 \mathrm{~mm}$ were defined as clinically insignificant residual stones (CIRF). Complications classified according to the modified Clavien Dindo scoring system.

\section{Statistical Analysis}

All statistical analyses were performed using SPSS version 22.0 (Statistical Package for Social Sciences for Windows; Chicago, IL, USA). BMI, age, stone burden, stone number, hospital stay, operation and fluoroscopy times, stone-free rates and CIRF were compared using One-Way ANOVA test. Intraoperative and postoperative complication rates were compared using the Pearson Chi-Square test. A p-value of $<0.05$ was considered statistically significant.

\section{RESULTS}

Demographic data of the patients and stones were presented in Table 1 and 2. The study was designed by the matched pair method, so all of the characteristic data of the patients and stones were statistically similar. Each group had 184 patients.

The stone-free status of the patients was checked three months after the last intervention to the stone by CT scan. The stone-free rate (SFR) of the study population was $80.8 \% ; 81 \%$ for Group 1, 83.7\% for Group 2 and $77.7 \%$ for Group 3. There was no statistically significant difference between the three groups among SFR ( $\mathrm{p}=0.346)$. CIRF was detected in $14(7.7 \%)$ patients in Group 1, 9 (4.9\%) in Group 2 and 7(3.8\%) in Group 3. CIRF status was also similar among the three groups $(\mathrm{p}=0.254)$. Operative outcomes were presented in Table 3.

Complication rates between the three groups were statistically similar $(\mathrm{p}=0.416)$. Three high-grade complications occurred; one patient of Group 1 and one patient of Group 3 had collecting system perforation also one patient of Group 1 died because of sepsis. Minor complications occurred in 35 (6.3\%) patients. Prolonged haematuria was recorded in 5 patients. No blood transfusion or any other interventions were required. Haematuria was disappeared by only oral hydration and rest. Sixteen patients had fever exceeding 38.0 C treated with antipyretics. Urinary tract infection was seen in 14 patients who were treated with parenteral antibiotics. All the complications were labelled in Table 4.

The mean operation time of the groups was 45.49 min, $47.74 \mathrm{~min}, 47.33 \mathrm{~min}$, respectively. There was no statistically significant difference between groups $(\mathrm{p}=0.371)$. Also, fluoroscopy times were similar $(\mathrm{p}=0.514)$. The mean fluoroscopy time was $41.43 \mathrm{sec}-$ onds for Group 1, 37.74 seconds for Group 2 and 43.76 seconds for Group 3. There was no statistically significant difference between groups for the hospitalization time $(\mathrm{p}=0.155)$.

Ureteral access sheath placement was not possible in 102 patients due to the ureteral stricture. The flexible ureteroscope was placed in the renal collecting system through a guidewire in those patients. Access sheath placement failure was similar among groups $(\mathrm{p}=0.245)$. 
Table 1. Patient Characteristics

\begin{tabular}{|c|c|c|c|c|}
\hline & Group 1 & Group 2 & Group 3 & $P$ value \\
\hline Number Of Patients & 184 & 184 & 184 & \\
\hline Gender (M/F) & $81 / 103$ & $82 / 102$ & $78 / 106$ & \\
\hline Age (year) & 50.94 & 51.26 & 52.74 & .363 \\
\hline Mean BMI $\left(\mathrm{kg} / \mathrm{m}^{2}\right)$ & 23.037 & 26.949 & 32.963 & \\
\hline History Of Urolithiasis & 18 & 50 & 49 & $<.05$ \\
\hline Urinary System Anomaly & 15 & 10 & 8 & .285 \\
\hline Antiaggregan-Anticoagulant Usage & 4 & 1 & 3 & .658 \\
\hline
\end{tabular}

M: Male; F: Female; BMI: Body Mass Index.

Table 2. Stone Characteristics

\begin{tabular}{lcccc}
\hline & Group 1 & Group 2 & Group 3 & P value \\
\hline Mean Stone Size $(\mathrm{mm})$ & 15.23 & 15.54 & 15.57 & .649 \\
\hline Mean Stone Number & 1.50 & 1.146 & 1.40 & .462 \\
\hline Laterality & & & & \\
Right & 101 & 97 & 90 & .605 \\
Left & 83 & 85 & 2 & 57 \\
Bilateral & 0 & 2 & 20 & 14 \\
Lower Calyx & 55 & 57 & 21 & 38 \\
Middle Calyx & 21 & 14 & 30 \\
Upper Calyx & 14 & 39 & 25 \\
Renal Pelvis & 40 & 29 & & \\
Ureteropelvic Junction & 30 & 24 & & \\
Multiple & 24 & & & \\
\end{tabular}

Table 3. Operative Outcomes

\begin{tabular}{lcccc}
\hline & Group 1 & Group 2 & Group 3 & P value \\
\hline Mean Operative Time (min) & 45.49 & 47.74 & 47.33 & .371 \\
Mean Flouroscopy Time (sec) & 41.43 & 37.74 & 43.76 & .514 \\
Mean Hospital Stay (day) & 1.10 & 1.01 & 1.07 & .155 \\
Stone Free Rates & $81 \%$ & $83.7 \%$ & $77.7 \%$ & .346 \\
Complication Rates & $8.2 \%$ & $7.6 \%$ & $4.9 \%$ & .416 \\
\hline
\end{tabular}

min: minute; sec: second. 
Table 4. Complications according to Modified Clavien-Dindo Scoring System

\begin{tabular}{lcccc}
\hline & Group 1 & Group 2 & Group 3 & P value \\
\hline Grade 1 & 9 & 8 & 4 & 3 \\
Grade 2 & 5 & 6 & 0 & \\
Grade 3A & 0 & 0 & 1 & \\
Grade 3B & 1 & 0 & 0 & $\mathbf{4 1 6}$ \\
Grade 4 & 0 & 0 & 0 & $\mathbf{8}$ \\
Grade 5 & 1 & 0 & $\mathbf{1 4}$ & \\
Total & $\mathbf{1 6}$ & & & \\
\hline
\end{tabular}

\section{DISCUSSION}

New technological developments of endoscopic instruments and laser lithotripters have made RIRS an alternative and favourite treatment option for renal stones. RIRS is a safe and effective minimally invasive procedure with high stone-free rate and has a low complication rate even for the stones larger than $20 \mathrm{~mm}$. It is an alternative treatment option to PNL with increasing popularity (7). Moreover, RIRS is a good option for renal stones in obese patients that surgery is challenging because of the complications related to obesity. The efficiency of RIRS for obese patients with renal stones has been evaluated and reported that BMI levels did not affect the stone-free rate and complication rates $(6$, 8). Chen et al. reported stone-free rate as $67.2 \%$ after single session RIRS and final success rate as $89.1 \%$ for renal stones between 20 and $30 \mathrm{~mm}$ size in obese patients (9). In another study, researchers evaluated the renal pelvis stones between 10 and $20 \mathrm{~mm}$ in obese patients and reported a stone-free rate of $90.4 \%$ (10). Alkan et al. evaluated RIRS efficacy for different BMI levels and reported $81 \%$ stone-free rate for normal-weight patients, $87 \%$ for overweight patients, $87.4 \%$ for obese patients and $85 \%$ for morbidly obese patients. There was no statistically significant difference between the four groups (11). In our study overall stone-free rate for the population was $80.8 \%$, and the final success rate was $86.1 \%$ if CIRF were stated as procedure success. In subgroup analysis, stone-free rates were $81 \%, 83.7 \%$ and $77.7 \%$ respectively, and there was no statistically significant difference between groups. Also, the final success rates were similar for three groups $88.6 \%, 88.6 \%$ and $81 \%$ respectively ( $\mathrm{p}=0.052$ ). Our study has shown similar outcomes as stated in the literature which BMI levels did not influence the success of RIRS procedure.
Sari et al. reported that the operation and fluoroscopy time were statistically similar in patients who underwent flexible ureteroscopy at different BMI levels. Mean operative time was 45.8 minutes for normal-weight patients, $45.1 \mathrm{~min}$ for overweight, $45.5 \mathrm{~min}$ for obese and 44 for morbidly obese patients. Also, the fluoroscopy time was 1.94, 1.85, 1.60 and 1.79 min for normal weight, overweight, obese and morbidly obese patients, respectively (12). In another study, Delorme et al. reported similar operative time for obese and non-obese patients (13). In our study, we found similar operative $(p=0.371)$ and fluoroscopy time $(p=0.514)$ between groups. Also, there was no statistically significant difference between groups for the length of hospital stay.

Although RIRS is accepted as a minimally invasive procedure for renal stones with higher stone-free rates and lower complication rates, some severe complications still can occur. Breda et al. reported that the overall complication rate for RIRS was $8 \%$, and the highgrade complication rate was $1.9 \%$ (14). In another study, Doizi et al. reported an overall complication rate of $2.44 \%$ with no high-grade complications, which are lower than reported before (6). In a systematic review, the overall complication rate in obese patients was $11.4 \%$, and most of these complications were classified as grade 2, according to the modified Clavien Dindo scoring system (15). In our study, the overall complication rate was $6.8 \%$. Although RIRS is a minimally invasive procedure we had a grade 5 complication. Renal collecting system perforation occurred in one patient during the ureteral access sheath placement and that patient died because of sepsis.

Altay et al. reported that flexible ureteroscopy and Holmium YAG laser lithotripsy is safe and effective 
treatment option for patients who were under longterm antiaggregant or anticoagulant therapy (16). They did not encounter any cardiac or thromboembolic adverse events and reported similar complication rates as in the literature. Eight patients were under long-term anticoagulant or antiaggregant therapy in our study and we did not encounter any complication or adverse event in those patients.

Retrospective nature of the study, not classifying morbidly obese patients as a subgroup and operations performed by more than one surgeon were the limitations of the study. Despite these limitations, our study has the largest patient number and designed with matched pair technique.

\section{CONCLUSION}

With technological development, RIRS became famous for the treatment of urolithiasis, even for the larger stones. Recent data in the literature showed that RIRS is safe and efficacious minimally invasive treatment modality both non-obese and obese patients who are challenging to set prone positioning. Also, RIRS is safe even for the patients who are under anticoagulant treatment which are accepted as a contraindication for open surgery, SWL and PNL. In this study, we have shown that it is a suitable option for all urolithiasis patients, even for obese individuals. Stone-free rates, length of hospital stay, operation times and complication rates in obese patients are similar with non-obese patients. However, prospective and randomized trials are necessary to compare the results.

\section{Acknowledgment}

No acknowledgments to declare.

\section{Conflict of Interest}

All authors declared that there is no conflict of interest.

\section{Financial Disclosure}

The authors declared that this study has received no financial support.

\section{Ethical Approval}

This study has been conducted retrospectively. The study protocol conformed to the ethical guidelines of the Helsinki Declaration.

\section{REFERENCES}

1. Organization WH. Overweight and Obesity. 2017 [cited 2017 October 11th]. Available from: http://www.who.int/ gho/ncd/risk_factors/overweight_text/en/.

2. Powell CR, Stoller ML, Schwartz BF, et al., Impact of body weight on urinary electrolytes in urinary stone formers. Urology. 2000; 55(6):825-830.

3. Trinchieri A, Croppi E, and Montanari E, Obesity and urolithiasis: evidence of regional influences. Urolithiasis. 2017; 45(3):271-278.

4. Choban PS and Flancbaum L, The impact of obesity on surgical outcomes: a review. J Am Coll Surg 1997; 185(6):593603.

5. Calvert RC and Burgess NA, Urolithiasis and obesity: metabolic and technical considerations. Curr Opin Urol. 2005; 15(2):113-117

6. Doizi S, Letendre J, Bonneau C, et al., Comparative study of the treatment of renal stones with flexible ureterorenoscopy in normal weight, obese, and morbidly obese patients. Urology. 2015; 85:38-44.

7. Aboumarzouk OM, Monga M, Kata SG, et al., Flexible ureteroscopy and laser lithotripsy for stones $>2 \mathrm{~cm}$ : a systematic review and meta-analysis. J Endourol. 2012; 26(10):1257-1263.

8. Chew BH, Zavaglia B, Paterson RF, et al., A multicenter comparison of the safety and effectiveness of ureteroscopic laser lithotripsy in obese and normal weight patients. J Endourol. 2013; 27(6):710-714.

9. Chen HQ, Chen ZY, Zeng F, et al., Comparative study of the treatment of $20-30 \mathrm{~mm}$ renal stones with miniaturized percutaneous nephrolithotomy and flexible ureterorenoscopy in obese patients. World J Urol 2018; 36(8):1309-1314.

10. Javanmard B, Razaghi MR, Ansari Jafari A, et al., Flexible Ureterorenoscopy Versus Extracorporeal Shock Wave Lithotripsy for the Treatment of Renal Pelvis Stones of 10-20 mm in Obese Patients. J Lasers Med Sci. 2015; 6(4):162-166.

11. Alkan E, Arpali E, Ozkanli AO, et al., RIRS is equally efficient in patients with different BMI scores. Urolithiasis 2015; 43(3):243-248.

12. Sari E, Tepeler A, Yuruk E, et al., Effect of the body mass index on outcomes of flexible ureterorenoscopy. Urolithiasis . 2013; 41(6):499-504. 
13. Delorme G, Huu YN, Lillaz J, et al., Ureterorenoscopy with holmium-yttrium-aluminum-garnet fragmentation is a safe and efficient technique for stone treatment in patients with a body mass index superior to $30 \mathrm{~kg} / \mathrm{m} 2$. J Endourol . 2012; 26(3):239-243.

14. Breda A and Angerri O, Retrograde intrarenal surgery for kidney stones larger than $2.5 \mathrm{~cm}$. Curr Opin Urol. 2014; 24(2):179-183.
15. Aboumarzouk OM, Somani B, and Monga M, Safety and efficacy of ureteroscopic lithotripsy for stone disease in obese patients: a systematic review of the literature. BJU Int. 2012; 110:374-380.

16. Altay B, Erkurt B, and Albayrak S, A review study to evaluate holmium:YAG laser lithotripsy with flexible ureteroscopy in patients on ongoing oral anticoagulant therapy. Lasers Med Sci. 2017; 32(7):1615-1619. 